\title{
Safety and effectiveness of percutaneous radiofrequency ablation in early stage renal cell carcinoma
}

\author{
HANG LIU ${ }^{1}$, CHANGZHONG GAO ${ }^{2}$ and HUALONG YU ${ }^{3}$ \\ Departments of ${ }^{1}$ Interventional Therapy and ${ }^{2}$ Radiology, Yidu Central Hospital of Weifang, Qingzhou, Shandong 262500; \\ ${ }^{3}$ Department of Radiology, The Affiliated Hospital of Qingdao University, Qingdao, Shandong 266100, P.R. China
}

Received June 10, 2016; Accepted October 3, 2016

DOI: 10.3892/ol.2016.5267

\begin{abstract}
The purpose of this study was to analyze the safety and effectiveness of percutaneous radiofrequency ablation (RFA) in early stage renal cell carcinoma. A total of 76 patients suffering from early stage renal cell carcinoma were selected and randomly assigned into the observation group (41 cases) or the control group (35 cases). Percutaneous RFA was used in the observation group, while retroperitoneoscopic radical operation of renal cell carcinoma was used in the control group, and the operative effects were compared. In the observation group, operation time, blood loss during operation, length of stay and incidence rate of complications were lower than those in control group $(\mathrm{P}<0.05)$. For both groups, serum C-reactive protein, interleukin- 6 and $\mathrm{T}$ lymphocyte counts at 1,2 and 3 days after operation were all increased; however, the control group had significantly greater increase for all the time points $(\mathrm{P}<0.05)$. For total effective rates, tumour-free survival times and survival rates, there were no statistically significant differences between the two groups $(\mathrm{P}>0.05)$. Percutaneous RFA has a reduced size of operation wound and a quick postoperative recovery time in the treatment of early stage renal cell carcinoma. It results in less inflammation and immunity-based injuries in the body and achieves the same clinical outcomes as retroperitoneoscopic radical operation of renal cell carcinoma.
\end{abstract}

\section{Introduction}

As a common tumour observed in urinary surgery, the incidence rate of renal cell carcinoma accounts for $5 \%$ of carcinoma cases in adults and is increasing by $4 \%$ per year. In addition, its prevalence tends to be higher among young people relative to other forms of carcinoma (1). With the development

Correspondence to: Dr Hualong Yu, Department of Radiology, The Affiliated Hospital of Qingdao University, 59 Haier Road, Qingdao, Shandong 266100, P.R. China

E-mail: yuhualong_qd@163.com

Key words: percutaneous radiofrequency ablation, early stage renal cell carcinoma, laparoscope of physical examination and imaging screening technology, the rates of early detection, treatment, and recovery of early stage renal cell carcinoma are improving. Surgical operation is the main treatment method for early stage renal cell carcinoma.

Retroperitoneoscopic radical operation of renal cell carcinoma has been established among micro-invasive methods and its resection rate, survival rate, incidence rate of complications and recurrence rate are close to those of open operation $(2,3)$. The development of radiofrequency ablation (RFA) has improved micro-invasive treatment techniques of small renal cell carcinoma. With the guidance of CT, ultrasound, or MRI, and by laparoscopic or open approach, RFA is performed by inserting monopolar or cluster electrodes into tumour tissue. Heat generated from ions surrounding the electrode needle are transferred to adjacent tissues around the tumour to make tumour tissue dry and dehydrated, causing coagulative necrosis. Therefore, rounded or spherical ablation areas are formed as a means to kill tumour tissues $(4,5)$. RFA has shown good clinical outcomes for patients who are in middle and late stage renal cell carcinoma and cannot receive open operations or are limited to palliative treatment (6). Currently, there are few reports regarding RFA treatment on early stage small renal cell carcinoma and there has been no prospective study analysis.

Therefore, the aim of the present study was to analyze the safety and effectiveness of percutaneous RFA, in comparison to retroperitoneoscopic radical operation, in the treatment of early stage renal cell carcinoma.

\section{Patients and methods}

Patient data. A total of 76 cases of early stage renal cell carcinoma that were diagnosed in Yidu Central Hospital of Weifang (Qingzhou, China) from January, 2011 to January, 2013 were selected for the study. Diagnoses were clinically confirmed through ultrasound, CT, intravenous urography and histopathology examination. Inclusion criteria were: i) No renal vein, inferior vena cava or renal pedicle lymph node involvement and no distant metastasis of the tumour; ii) diameter of solidary tumour of $<4.0 \mathrm{~cm}$; iii) clinical stage was classified as T1N0M0; iv) no abdominal infection or surgical history; and v) important organs, such as heart, lung and brain, were normal in routine examination before operation. Exclusion criteria were: i) Abnormal coagulation function; ii) abnormal 
Table I. Comparison of operation conditions between patients of the observation group $(n=41)$ and the control group ( $\mathrm{n}=35)$.

\begin{tabular}{lccr}
\hline Groups & Operation time (min) & Blood loss during operation (ml) & Length of stay (day) \\
\hline Observation & $51.8 \pm 9.7$ & $12.8 \pm 4.7$ & $6.9 \pm 1.2$ \\
Control & $101.3 \pm 14.7$ & $117.5 \pm 32.8$ & $10.7 \pm 3.3$ \\
t-test & 8.598 & 18.329 & 5.544 \\
P-value & $<0.001$ & $<0.001$ & 0.036 \\
\hline
\end{tabular}

Table II. Comparison of incidence rates of operative complications [cases, (\%)]

\begin{tabular}{|c|c|c|c|c|c|c|c|}
\hline Groups & Cases & $\begin{array}{c}\text { Acute renal } \\
\text { failure }\end{array}$ & Infection & $\begin{array}{l}\text { Delayed } \\
\text { bleeding }\end{array}$ & Seroperitoneum & $\begin{array}{l}\text { Abdominal } \\
\text { adhesion }\end{array}$ & $\begin{array}{c}\text { Total } \\
\text { incidence rate }\end{array}$ \\
\hline Observation & 41 & 1 & 0 & 1 & 1 & 1 & $4(9.8)$ \\
\hline Control & 35 & 3 & 1 & 3 & 1 & 2 & $10(28.6)$ \\
\hline$\chi^{2}$ & & & & & & & 4.448 \\
\hline P-value & & & & & & & 0.035 \\
\hline
\end{tabular}

contralateral renal function; and iii) follow-up materials were incomplete.

After reviewing protocol and risks with patients and their family members, we received informed and signed consent. Patients were then randomly assigned into either the observation group (41 cases) or the control group (35 cases). In the observation group, there were 27 males and 14 females, ages $35-69$ years, and with an average age of $53.5 \pm 12.3$ years. Their average tumour diameter was $2.73 \pm 0.85 \mathrm{~cm}$. In the control group, there were 22 males and 13 females, aged 32-67 years, and with an average age of $51.8 \pm 13.2$ years. Their average tumour diameter was $2.54 \pm 0.80 \mathrm{~cm}$. There were no statistically significant differences in the above factors between the two patient groups $(\mathrm{P}>0.05)$.

Study methods. Patients in the two groups were taken care of by the same operation and nursing team and all procedures were conducted based on standard medical procedures. For the observation group, ultrasound was used to guide percutaneous RFA treatment as follows: General anesthesia was administered with the patient in prone position. A radiofrequency probe was inserted under the guidance of ultrasound. RFA was then performed by passing the electrode through the tumour tissue, with routine biopsy. An open cold circulating pump and a radiofrequency generator were used to perform RFA for 1 cycle (12 min). The tissue temperature was set to remain elevated $>60^{\circ} \mathrm{C}$ after the treatment was stopped in order to ensure termination of tumour cells. Repeated points and frequencies of RFA were performed as necessary. For the control group, retroperitoneoscopic radical operation of renal cell carcinoma was performed, as follows: General anesthesia was administered with the patient's healthy side in lateral position and the waist elevated. The first puncturing hole was at the costal margin of posterior axillary line. A self-made balloon dilator was put through the incision to establish retroperitoneal space. The incision was extended at the costal margin of posterior axillary line and then the tumour was excised accordingly.
Resected kidney samples were put into self-made specimen bags to be sent for testing.

Observation methods. i) Operative conditions of the two groups were recorded and compared, including operation time, blood loss during operation, length of stay and incidence rate of complications after the operation. ii) Collection and comparison of serum C-reactive protein (CRP), interleukin (IL)-6 and T lymphocyte count changes was done before the operation and 1,2 and 3 days afterwards. iii) Response evaluation criteria in solid tumours was used to compare recent clinical effects between the two groups, including complete remission, partial remission, stable, and progress. iv) Follow-up was carried out on the two groups to compare tumour-free survival time and survival rate.

Statistical analysis. SPSS 22.0 statistical software (IBM SPSS, Armonk, NY, USA) was used for data processing and statistical analyses. Data were presented as mean values with \pm standard deviation. Comparisons between groups were made using independent samples t-tests and comparisons within one group at different time points were done by analysis of variance for repeated measures. Enumeration data were presented as cases or (\%) and the comparison between groups was made using Chi-square test. Comparison of ranked data was made using the Mann-Whitney U test. The Kaplan-Meier model was used to assess tumour-free survival time and log-rank test was used to assess survival distribution. For all tests, $\mathrm{P}<0.05$ was considered to indicate a statistically significant difference.

\section{Results}

Comparison of operation conditions. In the observation group, operation time, blood loss during operation and length of stay were all lower than those in control group, with the differences each statistically significant $(\mathrm{P}<0.05$, Table I $)$. 
Table III. Comparison of serum CRP, IL-6 and T lymphocyte count between groups.

\begin{tabular}{lcccc}
\hline Groups & Time & CRP $(\mathrm{mg} / \mathrm{l})$ & IL-6 (ng/l) & Lymphocyte count (x109/l) \\
\hline Observation & Before operation & $2.55 \pm 0.81$ & $1.83 \pm 0.25$ & $2.16 \pm 0.64$ \\
& 1 day after operation & $6.37 \pm 2.10$ & $5.42 \pm 1.42$ & $2.76 \pm 0.42$ \\
& 2 days after operation & $7.49 \pm 2.06$ & $6.67 \pm 1.85$ & $2.68 \pm 0.25$ \\
3 days after operation & $7.27 \pm 2.96$ & $6.31 \pm 1.16$ & $2.55 \pm 0.31$ \\
Control & Before operation & $2.49 \pm 0.78$ & $1.76 \pm 0.33$ & $2.33 \pm 0.72$ \\
& 1 day after operation & $7.73 \pm 2.29$ & $6.30 \pm 1.48$ & $2.88 \pm 1.06$ \\
& 2 days after operation & $8.43 \pm 2.20$ & $7.44 \pm 1.96$ & $2.74 \pm 0.57$ \\
& 3 days after operation & $8.35 \pm 2.67$ & $7.22 \pm 1.84$ & $2.60 \pm 0.61$ \\
\hline
\end{tabular}

CRP, C-reactive protein; IL, interleukin.

Table IV. Comparison of recent effects between patients in the two groups [cases, (\%)].

\begin{tabular}{lcccccc}
\hline Groups & Cases & CR & PR & SD & PD & Total effective rate \\
\hline Observation & 41 & $9(22.0)$ & $21(51.2)$ & $6(14.6)$ & $5(12.2)$ & $36(87.8)$ \\
Control & 35 & $14(40.0)$ & $10(28.6)$ & $7(20.0)$ & $4(11.4)$ & $31(88.6)$ \\
$\chi^{2}$ & & & 4.799 & & 0.000 \\
P-value & & & & 0.187 & 1.000 \\
\hline
\end{tabular}

CR, complete remission; $\mathrm{PR}$, partial remission; $\mathrm{SD}$, stable disease; $\mathrm{PD}$, progressive disease.

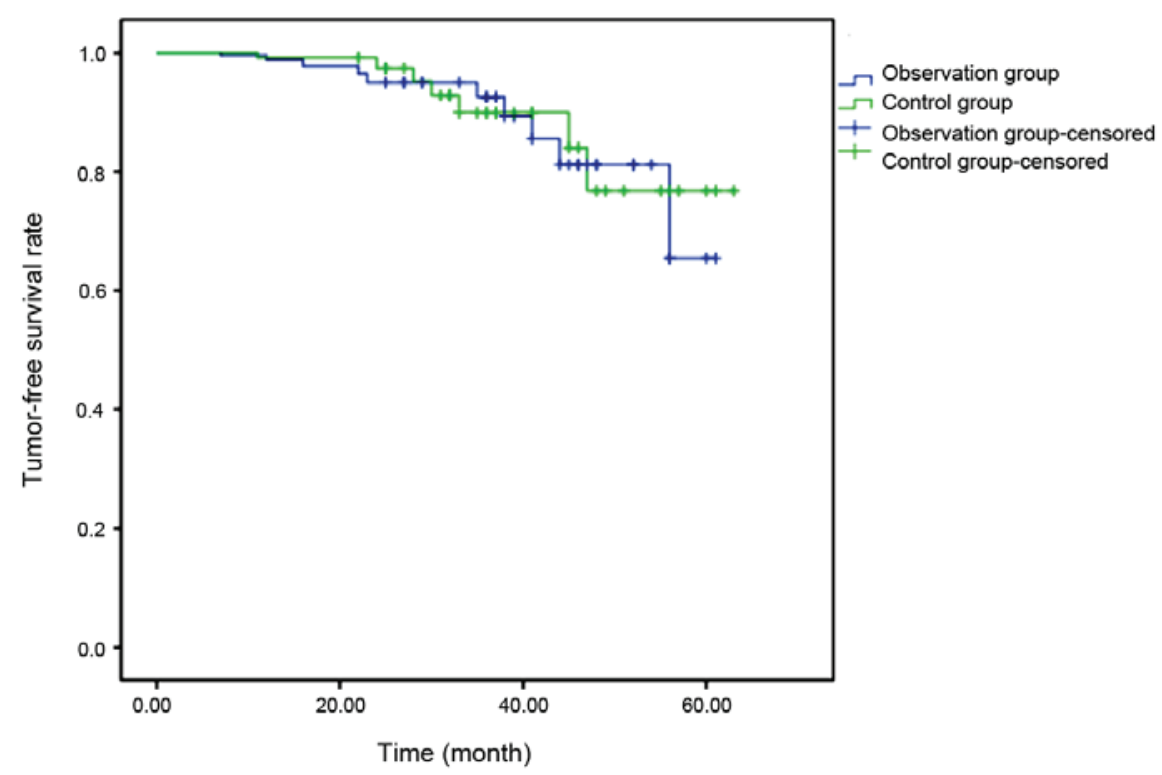

Figure 1. Comparison of tumour-free survival rates between the groups, over time. The blue line indicates the rate of the observation group ( $\mathrm{n}=41)$ and the green line indicates the rate of the control group $(n=35)$, with checks signifying patients censored during follow-up.

Comparison of incidence rate of operative complications. The incidence rate of operative complications in the observation group was lower than that of the control group and the difference was statistically significant $(\mathrm{P}<0.05$, Table II).
Comparison of serum CRP, IL-6 and T lymphocyte counts. For both groups, serum CRP, IL-6 and T lymphocyte counts on 1,2 and 3 days after operation were all increased over time $(\mathrm{P}<0.05)$. However, counts from the control group all showed a 
greater increase for all time points, compared to the observation group, and the differences were of statistical significance $(\mathrm{P}<0.05$, Table III).

Comparison of recent effects between patients in the two groups. The differences in recent effects between patients of the two groups were of no statistical significance ( $P>0.05$, Table IV).

Comparison of tumour-free survival time and survival rate during follow-up between the two groups. The median follow-up time after operation for the two groups was 4.8 years and there were no statistically significant differences in tumour-free survival time (43.6 vs. 45.7 months, $\chi^{2}=2.021$, $\mathrm{P}=0.125 ;)$ and survival rate $(88.6(31 / 35)$ vs. $85.4 \%(35 / 41)$; $\chi^{2}=0.005, \mathrm{P}=0.943$ ) between them (Fig. 1).

\section{Discussion}

It has been demonstrated by several studies $(7,8)$ that RFA can be used as an effective alternative as a minimally invasive treatment plan for localized tumours. It has been shown through cell staining techniques that, after RFA treatment, degenerative necrosis occurs to proteins of organelles in tumour cells within a short period of time, even with no structural or morphological changes of the tumour cells (9). Compared with partial nephrectomy, RFA results in less hemorrhage during operation, reduced postoperative convalescence, and expedited recovery time. Furthermore, RFA does not require blockage of blood flow to the kidneys and there is no warm ischemia period, thereby having less influence on renal function and reduced risks of kidney loss $(10,11)$. RFA of renal cell carcinoma was first performed laparoscopically and, with this as a basis, percutaneous RFA under ultrasound guidance is now used in the Yidu Central Hospital of Weifang and its application has achieved good clinical results. The result of the present study have shown that, in patients treated by RFA, operation time, blood loss during operation, length of stay and incidence rate of complications are lower than patients treated by established methods. For both groups of patients, serum CRP, IL-6 and T lymphocyte counts on 1, 2 and 3 days after operation were all increaed over time. Furthermore, counts from the control group all showed a greater increase for all the time points. For total effective rates after operation, tumour-free survival times and survival rates, differences between the two groups were of no statistical significance.

Clinical indication for treatment with RFA is diagnosis of a renal tumour with a diameter $<4 \mathrm{~cm}$ (12). In this study, early stage renal cell carcinoma patients with dorsolateral ultrasound of middle and lower kidney showing a tumour with a diameter $<4 \mathrm{~cm}$ were selected as study objects. Research has shown that there are different effects of RFA under different temperatures (13). The central part of the tumour is always the focus of RFA and the temperature must be controlled to $>60^{\circ} \mathrm{C}$ to enable accurate ablation and to realize tumour necrosis, and also to ensure that the physiological changes of the malignant tissue are irreversible. Whereas, changes of neighboring tissues are reversible when the temperature of healthy tissue is controlled to $<60^{\circ} \mathrm{C}$. No adverse effects have been observed from RFA, as the effects on healthy, neighboring tissue are too weak to cause concern.
Currently, the intended target patient population for RFA treatment is relatively small (14), which limits the ability to accurately test for clinical effects of RFA. Limitations of this study are the relatively small sample size of and the brief duration of follow-up time. Therefore, further research should be conducted on the safety and effectiveness of RFA to provide further clinical evidence.

Pathological reactions caused by a stress response to surgical operations, such as immunosuppression and metabolic disturbances, are related to tumour necrosis, nutritional status and prognosis to some degree $(15,16)$. It has been widely shown that changes in serum CRP, IL- 6 and T lymphocyte counts in peripheral blood are indices of immune response after tumour operation $(17,18)$. The results of this study have indicated that the above indices for the two groups of patients have increased following the operation, suggesting a stress response to the operative wound and tumour necrosis. However, the serum levels of the indices at time points following the operation in the control group were higher than those in the observation group, indicating that RFA has specific effects in alleviating postoperative inflammation and immune reaction. Further research is required regarding the relationship between treatment effects, tumour-free survival time and survival rate.

In conclusion, percutaneous RFA has advantages in treating early stage renal cell carcinoma, such as a reduced operative wound size, faster recovery times, and a reduced inflammatory response. Furthermore, RFA achieves the same clinical outcomes as the retroperitoneoscopic radical operation of renal cell carcinoma. Therefore, results of this study support RFA being recommended in clinical applications against early stage renal cell carcinoma.

\section{References}

1. Yung KW, Yung TT, Chung CY, Tong GT, Liu Y, Henderson J, Welbeck D and Oseni S: Principles of cancer staging. Asian Pac J Surg Oncol 1: 1-16, 2015.

2. Nozaki T, Iida H, Morii A, Fujiuchi Y, Komiya A and Fuse H: Use of the laparoscope holder for liver retraction during urological laparoscopic surgery. Curr Urol 6: 99-101, 2012.

3. Kamai T, Furuya N, Kambara T, Abe H, Honda M, Shioyama Y, Kaji Y and Yoshida K: Single minimum incision endoscopic radical nephrectomy for renal tumors with preoperative virtual navigation using $3 \mathrm{D}-\mathrm{CT}$ volume-rendering. BMC Urol 10: 7, 2010.

4. Jun HY, Ryu JH, Byun SJ, Jeong CW, Kim TH, Lee YH and Yoon KH: Combined radiofrequency ablation and double anti-angiogenic protein therapy to increase coagulation efficacy: An experimental study in a murine renal carcinoma model. Korean J Radiol 16: 776-782, 2015.

5. Modabber M, Martin J and Athreya S: Thermal versus impedance-based ablation of renal cell carcinoma: A meta-analysis. Cardiovasc Intervent Radiol 37: 176-185, 2014.

6. Kroeze SG, van Melick HH, Nijkamp MW, Kruse FK, Kruijssen LW, van Diest PJ, Bosch JL and Jans JJ: Incomplete thermal ablation stimulates proliferation of residual renal carcinoma cells in a translational murine model. BJU Int 110 (6 Pt B): E281-E286, 2012.

7. Chan AA, Ahrar K and Matin SF: Ablative therapies in renal cell carcinoma. Minerva Urol Nefrol 63: 237-250, 2011.

8. Kong WT, Zhang WW, Guo HQ, Qiu JL, Tang M, Jiang ZM, Shen Y, Li XG and Zhang SW: Application of contrast-enhanced ultrasonography after radiofrequency ablation for renal cell carcinoma: Is it sufficient for assessment of therapeutic response? Abdom Imaging 36: 342-347, 2011.

9. Prokhorov DG, Shkol'nik MI, Shumskiǐ IA and Belov AD: Application of radiofrequency ablation for treatment of localized renal carcinoma. Vopr Onkol 54: 507-511, 2008 (In Russian). 
10. Cahill T, Chen XL, Lee JW, Weiss M, Chang VT and Cella D Principles of radiofrequency ablation for cancer. Asian Pac J Surg Oncol 1: 47-58, 2015.

11. Ramirez D, Akca O, Delluc A, Reaume N, Haddock P and Chen XL: Staging of renal cell carcinoma. Asian Pac J Surg Oncol 2: 281-290, 2016.

12. Powles T, Zhao S, Gorbonos A and Kapoor A: Treatment strategies for renal cell carcinoma. Asian Pac J Surg Oncol 2: 301-316, 2016.

13. Chang X, Liu T, Lin Y, Yu J and Liang P: Radiofrequency ablation for renal cell carcinoma. Asian Pac J Surg Oncol 2: 351-360, 2016.

14. Wendler JJ, Friebe B, Baumunk D, Blana A, Franiel T, Ganzer R, Hadaschik B, Henkel T, Köhrmann KU, Köllermann J, et al: Focal therapy for small renal masses: Observation, ablation or surgery. Urologe A 55: 594-606, 2016 (In Russian).

15. Reichle A, Grassinger J, Bross K, Wilke J, Suedhoff T, Walter B, Wieland WF, Berand A and Andreesen R: C-reactive Protein in patients with metastatic clear cell renal carcinoma: An important biomarker for tumor-associated inflammation. Biomark Insights 1: 87-98, 2007.
16. Yang L, Wu X, Wang D, Luo $\mathrm{C}$ and Chen L: Renal carcinoma cell-derived exosomes induce human immortalized line of Jurkat T lymphocyte apoptosis in vitro. Urol Int 91: 363-369, 2013.

17. Figel AM, Brech D, Prinz PU, Lettenmeyer UK, Eckl J, Turqueti-Neves A, Mysliwietz J, Anz D, Rieth N, Muenchmeier $\mathrm{N}$, et al: Human renal cell carcinoma induces a dendritic cell subset that uses T-cell crosstalk for tumor-permissive milieu alterations. Am J Pathol 179: 436-451, 2011.

18. Granov AM, Molchanov OE, Karelin MI, Shkol'nik MI and Krotova OA: Influence of immunological parameters on the effectiveness of systemic and loco-regional immunotherapy in disseminated renal carcinoma. Vopr Onkol 55: 580-585, 2009 (In Russian). 